\title{
C. elegans takes out the trash
}

Newly discovered cellular 'trash bags,' termed exophers, offer insight into maintaining a healthy brain.

The life of C. elegans runs its course in just 21 days. With its transparent body and precise cell counts ( 959 cells total, and 302 neurons in the adult hermaphrodite), the inner workings of these little worms can be tracked over entire lifespans. It was during a longitudinal study on aging that Ilija Melentijevic, then an undergraduate in Monica Driscoll's lab at Rutgers University, noticed small, transient fluorescent spots appearing among the neurons of the worms he was tracking. Melentijevic, not convinced these were mere cellular artifacts, presented Driscoll with a time-lapse video capturing the formation and splitting of one of these structures from a neuronal soma. He had discovered a cellular trash bag, which he coined an "exopher" (Nature 542, 367-371; 2017).

From the start, Melentijevic had a gut feeling of their function. "I was working with the assumption that somehow neurons can live for one hundred, two hundred years in some animals without dividing, so there must be some way that they can maintain themselves," he explains. With the idea in mind that exophers play some role in neuronal maintenance, the lab needed to figure out how to prompt their formation. So they made trash.

They started, Driscoll explains, by creating C. elegans strains that produce protein aggregates analogous to those found in neurological diseases like Alzheimer's and Huntington's disease. As expected, exophers were observed at neurons containing these aggregates; after the tangled proteins were ferried away, there was also evidence that the neurons that had formed exophers were healthier than those that had not.

The team also created physiological trash, genetically and pharmacologically dismantling the main processes responsible for normal intra-cellular protein degradation. Again, the exophers formed, picking up the slack and transporting waste out of the cell. Driscoll suggests that the traditionally investigated processes for intracellular degradation can be thought of as akin to a garbage disposal. "And let's face it, the

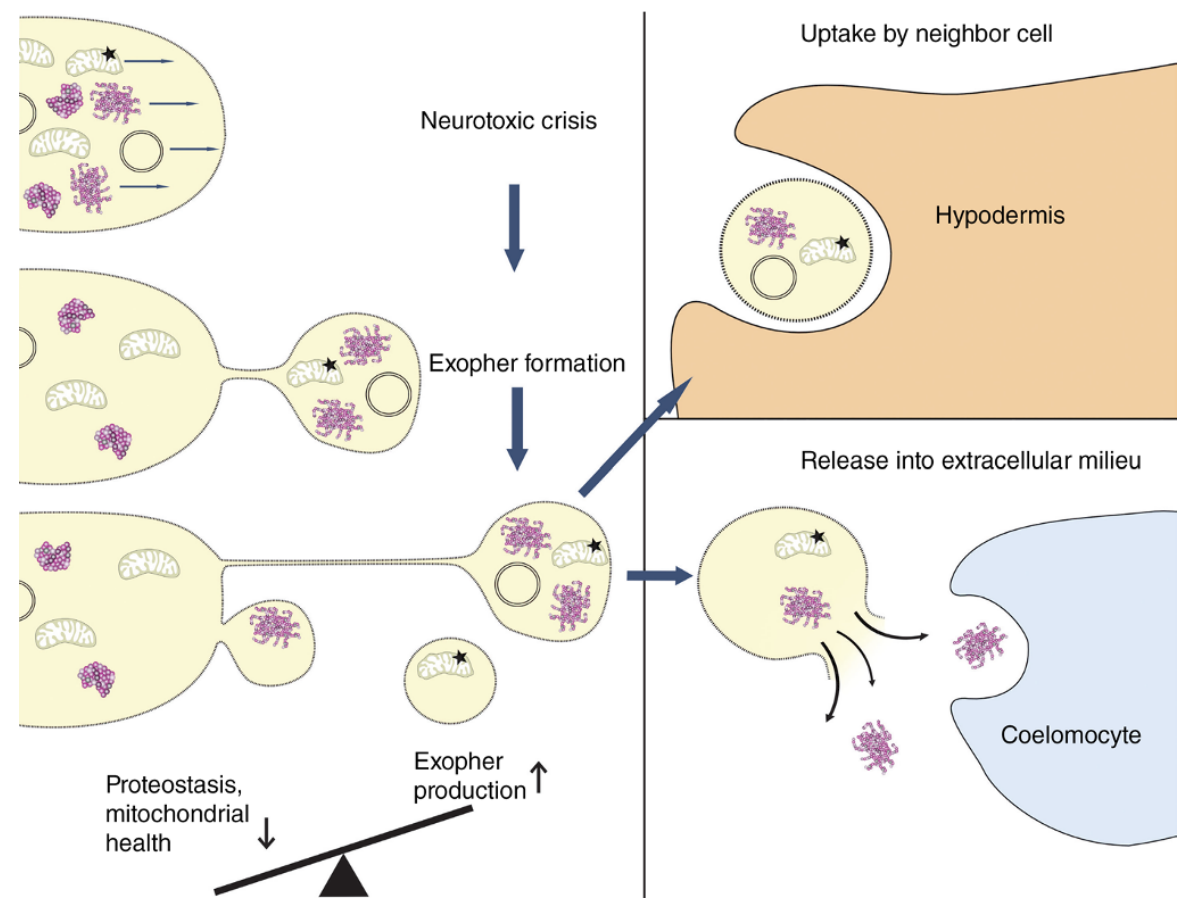

Working model for a proposed exopher role in proteostasis. Adapted from Nature 542, 367-371; 2017.

garbage disposal is not going to take care of all your trash in the house," she says. It seems to the researchers that exophers offer C. elegans another way to remove waste in neurons that exceeds internal capacity.

Though manipulating internal protein stress can induce their formation, exophers don't appear to be just a back-up system when waste gets out of hand. Driscoll says, "We also saw it coming on a schedule. In young adults, there's like a trash day, and the neurons throw out their trash in this little time window." In addition to helping keep adult neurons healthy and clutter-free, exophers might also be critical in normal neurological development.

If exophers are conserved features in more complex brains, like those of humans, the implications for neurological research are immense. There are hints of such conservation in the literature, Melentijevic says, in studies that have documented the transport of things like polyglutamine and mitochondria between neurons and glial cells in Drosophila and in mice, respectively. But unlike C. elegans, higher organisms are a bit more opaque, which might make capturing exopher formation more challenging.
"Tissue in human brain and mouse brain is really complicated, so I think it's going to be technically hard to track these things," says Driscoll, "which is why I think it's important to dissect the process in the worm."

She hopes further work in C. elegans will reveal molecular signatures that could then be looked for in other organisms. "Our understanding and our experience is that the things we study at the basic level [in C. elegans] are maintained in humans," she explains, "so by dissecting things out, we can figure out the basic biology and that gives us a handle on the things to look for in humans."

In the meantime, the lab is hard at work with their worms. "We're like kids in a candy shop," remarks Driscoll. Melentijevic has joined as a PhD candidate, and he and others in Driscoll's lab are actively pursuing numerous mechanistic questions about exopher formation and function as well as their role in healthy and diseased brains. The team is also looking for colleagues to collaborate on mammalian parallels. The bags may have been identified, but there's still much to learn about taking out the trash.

Ellen P. Neff 